\title{
Female Identity Diffusion in Helena Viramontes' Selected Short Stories: Postmodern Perspective
}

\author{
Abdullah Fawaz Al-Badarneh \\ The Hashemite University \\ Zarqa, Jordan \\ Baker Bani-Khair \\ Moh'd Ahmad Al-Omari \\ The Hashemite University, Zarqa \\ Jordan
}

\begin{abstract}
This article is ultimately concerned with exposing the postmodern theme of identity diffusion in Viramontes' selected short stories: "Growing," "The Broken Web," "The Cariboo Cafe," and "Neighbors." The main focus of this study is to shed light on the position of Mexican American women that ultimately influences their identities to be postmodern. The paper reflects Mexican American women's suffering, alienation and oppression. Such postmodern themes of fragmentation, alienation, dislocation, and disempowerment on the side of the Mexican American woman came as a result of internal social and cultural abnegations, on one side. On the other side, it is the product of the socially and culturally racist society they live in. Postmodern themes of loss, diffusion of reality, alienation, and fragmentation are examined in Viramontes' four selected stories and, particularly, in the female characters. Upon meticulously considering these female figures, one can reach a common ground that brings them all together. The significance of this research comes from unraveling oppression and its reflection on Mexican American women.
\end{abstract}

Keywords: Mexican American Women, Alienation, Disempowerment, Oppression, Dislocation, Assimilation, Patriarchy

\section{Introduction}

One can claim that Mexican American women's suffering is two folds: they have been suffering because they are women and because they are Mexicans. Foregrounding the protagonists' double consciousness, fragmentation, and power relations, this article obviously exposes their identities as unstable, fragmented, and torn between two opposing worlds: the past and the present, the world of traditions and that of modernity, and culture and community. Of course, belonging to different ethnicity enhances and amplifies such dilemma. In the introduction of Reclaiming Identity, Paula Moya claims that "ethnic studies scholars and members of various student groups, for example, continue to deploy identity as an organizing principle in their scholarly, political, and activist endeavors" (P. 4). Therefore, identity seems to be the organizing principle that gathers together Viramontes' protagonists of the selected stories.

\section{Decentering Female Identity in Viramontes' "Growing"}

As the short story, "Growing" opens; the reader is struck by the amount of tension present in the story. The protagonist, Naomi, expresses her dissatisfaction at the way her father who represents the traditional Mexican patriarchy decentres her identity by distrusting her, and for nothing other than being a woman. In his essay entitled "Postmodern Man: Psycho- Cultural Responses to Social Trends," Vytautus Kalvolis defines the postmodern personality as "one characterized by the sense that both polarities of a great many of these dilemmas are contained, in an unresolved form, with one's own experience" (P. 445). These dilemmas include alienation, lack of satisfaction, need to reassert individual and group uniqueness, and need for unshakable points of reference which are all present in the underlying identity of Naomi. Therefore, such "polarities" with all the dilemmas they entail stem from the fact that Mexican American adolescents, like Naomi, are culturally hybrid and self- diffused personalities whose real identities are torn between two worlds: the world of the father, of the past and that of the new American liberal society and that of modernity. Therefore, Naomi reacts in a very courageous way, though still developing, when she confronts her mother opening all eyes to the fact that life in the United States of America is different from that in Mexico. In this context, she says addressing her mother, "Ama, the United States is different. Here girls don't need chaperones. Parents trust their daughters ... I am too old for that. I am an adult" (P. 36). 
Such generational gap between Naomi and her father with all its new contents of the new American life is pregnant with disruption and detachment inside the Mexican American family. In their article entitled, "The Impact of Acculturation in Mexican American Families on the Quality of Adult Grandchild-Grandparent Relationships," Meril Silverstein and Xuan Chen define the term "acculturation" as: the process by which immigrant groups assimilate into a dominant culture. Implicit in most definitions is that the minority ethnic group will incrementally adopt the ways of the majority culture ... we anticipate the younger members of immigrant families will be more likely than their elders to adopt the values and behavior of the dominant culture (Pierce, Clark, \& Kaufman, 1978) and the larger the resulting generation gap, the more grandparent- grandchild relationship, in Mexican American families will be disrupted (P. 189).

This is the exact case with Naomi who is a representative of the New Mexican American generation. She is easily assimilated and acculturated into the American lifestyle, but her father who represents the old generation is still living his memories of the traditional Mexican lifestyle. Such conflict ultimately leads to Naomi's fragmentation and selfdiffused identity we are talking about. The kind of violent treatment Naomi gets at home renders her identity insecure and oppressed. Such fragmentation between the two worlds brings into mind the double consciousness of the adolescent protagonist as one unstable and insecure. Du Bois uses a metaphor to describe this idea of double consciousness as he calls it "the life within the veil" (qtd. in Gallego, P. 15). That is, Naomi who is passing into womanhood is oppressed and unable in a way to render that passing successful because of the authority of her father that pulls her backward. Thus her real identity is suffering being stuck on the purgatory of passing. She has to do something about this or else she might go insane. What is "within the veil" of Naomi is a repressed personality or a division of her character that will no longer ease her of a severe psychological torment. This feeling of the double consciousness brings confusion and alienation into the protagonist's inner psyche.

Such fragmentation is so obvious and recurring in the story. Just in the first few pages of the narrative, one can trace this powerful postmodern theme of fragmentation. The narrator of the story describes Naomi's father in a way as a despot who dictates unjust rules to be followed by his family members with no hope of dialogue or argumentation. In this context, the narrator is describing him: "he thundered like a great voice above the heavens, and that was the end of any argument, any question, because he said those words not as a truth, but as a verdict, and she [Naomi] could almost see the clouds parting, the thunderbolts breaking the tranquility of her sex" (P. 36).

Under such oppression, Naomi feels incarcerated all the time. Her identity suffers conflict and fragmentation whether she should follow the dictates of her father who has put her under surveillance all the time or she will rebel against such tyranny because Naomi stands for the young Mexican American woman who is able to regain her lost sense of identity and independence. As the story develops, Naomi stands watching her friends playing baseball. Before she gets her maturity, she was allowed to participate in the game, but now it is not allowed for her to do it because she is a woman. After taking a long time living in a conflict considering whether to play or just to watch, Naomi makes her decision to play that she is "no longer concerned with her age, her menstruations, her breasts that bounced with every jump. All she wanted was an out at home plate. To hell with being benched. "Throw it to me," she yelled" (P. 41). Thus one can argue that what we have here in this story is a movement from identity diffusion to that of identity formation in the same way Naomi moves from the state of adolescence to that of maturity. However, Naomi needs to do a lot to get her identity well shaped. She is still suffering the input of her patriarchal domestic environment.

\section{Alienation and Fragmentation in Viramontes' "The Broken Web"}

Postmodern themes of loss, diffusion of reality, alienation, and fragmentation can also be traced in Viramontes" "The Broken Web" and particularly in the three female characters, Martha, the unnamed wife of Tomas, and Olivia, Tomas's lover. Upon meticulously considering these female figures, one can reach a common ground that can bring them all together although there is a generational gap between Martha on one side and the other two women on the other side. What brings these women together is the same feeling of loneliness and insecurity they all pass through. In a way their attachment to reality is undermined by the forces of patriarchy and oppressive internal and external life conditions that rendered all of them as powerless and victims of their circumstances. As the story starts, we meet Martha who appears as if hypnotized by the priest in order to relieve her of a tremendous psychological distress she is unable to tackle by herself. She repeats the word "asleep" many times that we as readers become unsure whether she was conscious or unconscious as she confesses her distress to the priest like when she says: "It's like a nightmare. I close my eyes and there is darkness. I think I am asleep, then ..." (P. 54) Therefore, the demarcation line between reality and dream in Martha's case has got no real distinction. It has got no censor that her dreams start plunging into her reality and her all existence has become centerless which is something at the heart of post modernism. 
Part of the postmodern filtration in the story is the structure of the story itself. In her essay entitled, "Hungry Women" Borderlands Mythos in Two Stories by Helena Viramontes," Wendy Swyt describes the story as full of juxtapositions and fragments saying: "after the narrative shifts abruptly between scenes just before and during the murder of Tomas, the following fragments focus on the explanations of Tomas, his wife, and his love. Olivia" (P. 192). This indicates that the story in structure and in theme is postmodern. The statue of Jesus is so significant in the story. For a while, Martha is comforted to see that statue present in the living room, but it was shattered down by the bullet her mother used to kill her father, Tomas. Thus, the statue of Christ functions, as Swyt is pointing out, as a "symbol of multiple recuperation ... as a sort of comfort" (P. 193). But the breaking of the statue leaves Martha uncomforted and unrelieved. That is why Martha is "unburdened or [not] liberated by her confession" (P. 192).

Likewise, the unnamed wife of Tomas and his love Olivia experience more or less similar postmodern themes of alienation, lack of communication, and fragmentation through their relationship to Tomas whose presence in the story is also caught between two worlds; that is, he is all the time between Mexico and the borderland of the United States working on passing Mexicans without legal papers into America for money. Thus, his existence is always in danger by the police. Such a person who is unable to provide security for himself, he is, for sure, will be impotent to do the same for his wife and lover. All the time the two women live in loneliness and their existence can best be described as decentered. For Olivia, she is forsaken by her former lover who left her two children to take care of. Her relationship with her sons lacks communication that "she never knew exactly when her sons came home nor she herself would ... she never played mother and they, in turn, never asked her to" (P. 58). Her concern about her physical beauty may be said to stem from her fear to lose Tomas. That is why she keeps looking in the mirror, so she may find security with Tomas in case she remains beautiful.

The unnamed wife of Tomas, just like Olivia, has no reference point. Though she is married, but her husband is unable to give her the happiness she is looking for. On the opposite, he betrays her with other women that she grows furious and shoots him. This unnamed woman responds to her husband's tyranny with a similar even stronger act of retaliation. First, "she had tried to defy the rules by sleeping with another man" (P. 60), then, she murdered her husband in a rebellious manner that had never happened before. But still after the murder, Tomas's wife is unable to regain her healthy well established identity. She continues to go through psychological fits all the time as Martha's aunt tells her about her mother. Therefore, the identity of this woman remains fragmented and insecure.

Thus, these postmodern concepts of double consciousness and fragmentation lead the females in the story to have different images that characterize what is known in postmodernism as "the loss of the real," (Barry, P. 87) that is, the real self or the real identity of the character. In other words, as unitary subject, each of the women represents an overall sign, but because this sign has double realities, the outside reality loses its connection within the inside reality, and the result is "a stage of emptiness" or "a hyper-reality" (Barry, P. 87) in which clear demarcation lines or distinctions are blurred in a way that there becomes no correspondence between the outside personality and the inside one, or it becomes very hard to identify. For these women, the outside reality is oppression, insecurity, patriarchy, and racist society, and the inside reality is a vulnerable woman who seeks love and warmth. When these two realities clash together and against each other, the result yields a fragmented female identity that is unable to belong to any party or ideology.

Naomi, Martha, Olivia, and Tomas's wife who each can be represented as a sign reach this stage of identity crisis that is suffering emptiness and loss through different stages. According to Baudrillard, the first stage is one in which "the sign represents a basic reality" (Barry, P. 87). We can trace this principle in the stories as the following: each of the women is supposed to have a sort of reference point that can guarantee a basic reality of peace and stability for all of them. For example, Martha's central reference point is being an innocent child who is supposed to grow up in a warm loving family. Olivia' reference point should be one as a loving mother and wife, but she was deserted by her husband. Tomas's wife is also supposed to live in happiness with her husband and children, but Tomas is unfaithful and disgusting to her.

The second stage for the sign to reach its final destination of emptiness is that "it misrepresents or distorts the reality behind it," and it also "disguises the fact that there is no corresponding reality underneath" (Barry, P. 88). This kind of repressing one consciousness in favor of a more desirable one is really felt in the story when Naomi ignores her father's instructions not to play with the other boys, when Tomas's wife starts liking to be alone rather being with an unfaithful husband, and when Olivia starts having an affair with Tomas. In the final stage of the Baudrillardian scheme for the sign to lose its centre and to start belonging to an unstable consciousness, it "bears no relation to any reality at all" (Barry, P. 88). This final stage is best expressed in Tomas's wife's murder of her husband, Olivia's detachment from her reality, and Martha's uncomforted distress. The ultimate result in the story is a "broken web" just as the title of the story suggests. 


\section{Dislocation and Identity hegemonizing in Viramontes" "The Cariboo Café"}

"The Cariboo Cafe'" is another story by Viramontes where one can find Mexican female characters suffering identity diffusion that comes as a result of social and cultural oppression. The character of the refugee woman in the story is the embodiment of the Mexican victimized woman who sends her five-year child into the street to get a mango and never to see him again. He is arrested by the Anglo police. The result is a woman who becomes crazy. Her diffused identity is a result of a border interaction in which she is the loser and her defeat is inevitable at the end. That is why the story ends with a bullet in her head. In their book, entitled, Gente Decente: A Borderlands Response to the Rhetoric of Dominance, Leticia Magda and Garza Falcon point out that "her [ the refugee woman] recollections reveal that the site of struggle for this woman has not been situated in the streets but in her home, which, without Geraldo, can no longer be her home" (P. 205). That is why the woman feels dislocated and keeps saying all the time: "without Geraldo, this is not my home; the earth beneath it, not my country. This is why I have to leave" (P. 75). Such postmodern feelings of alienation and dislocation the woman experiences come as a result of the Anglo-American hegemony that is in power. Thus, one can say that power plays a major role in setting the rules and forming psychological personalities. This idea of power dichotomy is expressed by the refugee woman when she says: No matter where we turn, there are rumors facing us, and we try to live as best we can under the rule of men who rape women then rip their fetuses from their bellies. Is this our home? Is this our country? I ask Maria. Don't these men have mothers, lovers, babies, sisters? Don't they see what they are doing? (P. 76)

Apparently, the refugee woman refers here to the Anglo- Americans who abuse and rape Mexican women dictating superiority out of power based relations. All the tension brought into the refugee woman's life springs from the fact that she is caught between two unequal powers or borderlands. Had she been solely in Mexico, she will be happy with her son though poor and she will not go through the psychological, painful distress, but her crisis causes her fragmentation between two countries. In his essay, Henry Giroux speaks of race as a crucial element and "a defining principle of identity and culture ... as a maker of difference" (P. 231). To the refugee woman, this rule does not apply. Her resulted identity is one of difference not one of unity. It is the same as the label of the Café, "the Zero Zero Cafe'" in which the word "Cariboo" is totally undermined. So here is a sort of analogy between her identity and the incomplete label.

\section{Diffusion and Generational Gap in Viramontes" "Neighbors"}

Viramontes' "Neighbors" also marks Aura Rodriguez as a self-diffused female identity for a lot of reasons. Most importantly, her memory of the past struggle her folks used to have against their Anglo-American oppressors leaves an unabridged gap between her and the New Mexican American generation who has changed from great heroes to mobsters. The narrator of the story expresses this idea when he says" "people of her [Aura] age died off only to leave their grandchildren with little knowledge of struggle" (p. 109). Interestingly and paradoxically, such realization of Aura of her all around circumstances renders her character as centerless and isolated from all around her. All she wanted in life is to be alone and to die in peace because she is physically living in the new American world, but spiritually she is living on her memories of her people's great past. Aura's mind can process nothing of the products of the new world. Her main interest is in her garden, flowers, and rose bushes that remind her of her past. Therefore, she is torn between two worlds: the past that connotes struggle and pride for her and the present that embodies "the alienating effects of displacement" (Magda, p. 210). In her book, Magda refers to the life force that keeps Aura's personality in a way stable. In this context, Magda says: The struggle is what is important to the seventy-three-year-old Aura, but the young people who surround her know nothing of what she and her generation lived. All they know or will ever know is a sense of defeat that has no history. Because they know nothing of the struggles, they have no sense of the origins of their defeat, or how they have gotten to the place their present world assigns them. The past for them is unaccounted for (p. 211).

That is why Aura experiences such alienation and dislocation in spite of the fact that she is living in a Mexican neighborhood among her people. In his article, Kalvolis points out that "the concern with alienation vs. participation (Kenistony, 1967, 1968) is closely involved with the dilemma or separation vs. fusion" (p. 438). Thus, there grows an overlapping conflict in the Aura's emotions towards her people. Such confusion or vacillation in her emotions towards her people is so much obvious in her decision to call the police for the boys who keep annoying her and in her regret that she made that decision. In a way, she feels that she has betrayed her people or at least brought the enemy at her home. Magda describes this incident of calling the police in his own words: "Aura's calling of the police had broken a silent neighborhood code. She had invited the unwanted oppressors into the neighborhood and provided the justification they needed to abuse the boys" (p. 213). That is why Aura feels depressed about the fact that she had to call the police who are originally the oppressors of her people in order to oppress her new oppressors. However, she still feels sympathetic towards her people. 
Power relations also contribute to Aura's postmodern sense of displacement, anger, and oppression. First of all, she is an old woman in her seventies who "could not even grasp a glass of water" (p. 115). Second of all, she is alienated by her own people who have said nothing against her oppressors and also by her larger society that she despises. The concept of power is defined by Fokkema in his article, "Postmodern Characters" as a "strong manifestation of the modality of being able to" (p. 184), so it has to do with achievement, and since "the postmodern character is, in the most general sense, caught up in power relations constituted by history, its paranoid beliefs, other narratives ... its autonomy is endangered or lost" (p. 184).

This is the case with our female protagonist. Because she is disempowered by her age and by her society, her "autonomy is endangered," but Aura rejects such disempowerment when she takes her grandfather's pistol in her own hand. Deciding to defend herself against outside attacks by the gangsters who kept threatening her, Aura visits her past through searching in the old boxes for a means of protection till she finds the pistol. In their article, JoAnn Pavletich and Margot Backus speak of the pistol saying: "the only item that retains cultural power that has not been drained or debunked by recent events is the pistol, a historic symbol of Chicano self- assertion and heroic defiance" (p. 141). For Aura, it is a moment of resistance and one of restoring the past glories of struggle and defiance. For Aura, it is really a hard moment to call the police. To her, "the world was getting too confusing now" (p. 115) that she herself gets confused and not sure whether she is making the right decision or is it because she is oppressed. Thus her character can be described in postmodern terms as "fluid, contingent, and socially constructed" (Huddy, p. 127).

\section{Conclusion}

In conclusion, one can say that Viramontes' female protagonists presented in these four stories, in spite of the generational gap, represent Mexican American women who suffered internal and external oppression, by internal, I mean; immediate oppression by their Mexican patriarchy, and by external, I mean; the Anglo Americans like the police in "Neighbors" who took the call as a justification to abuse the Mexican children. The female characters in Viramontes' stories are a "blend of strength and weaknesses, struggling against lives of unfulfilled potential and restrictions forced upon them by their sex" (Viramontes, Introduction,p. 1). Such double oppression renders the female protagonists in the stories as postmodern identities whose feelings are a blend of alienation, fragmentation, displacement, and anger all throughout the stories.

\section{Works Cited}

Barry, P. (1995)Beginning Theory: An Introduction to Literary and Cultural Theory. Manchester: Manchester University Press.

Fokkema, A. (1991) Postmodern Characters: A Study of Characterization in British and American Postmodern Fiction. Amsterdam: Rodopi.

Giroux, H. (1999). "Rewriting the Discourse of Racial Identity: Toward a Pedagogy and Politics of Whiteness." Becoming and Unbecoming White: Owning and Disowning a Racial Identity.Ed.Clark, Christine and James O'Donnell. Westport: Bergin \& Garvey, 258-320

Huddy, L. (2001). "From Social to Political Identity: A Critical Examination of Social Identity Theory."Political Psychology, Vol. 22, No. 1,127-156.

Kavolis, V. (1970). "Post- Modern Man: Psychocultural Responses to Social Trends.”Social Problems, Vol. 17, No. 4, 435-448.

Moya, P. (2000)."Introduction."Reclaiming Identity: Realist Theory and the Predicament of Postmodernism.Moya, Paula and MichaelHames-Gracia. Ed. Berkley: University of California Press, 2000, 1-29.

Pavletich, J. and Margot G. B. (1994). "With His Pistol in Her Hand: Rearticulating theCorrido Narrative in Helena MaríaViramontes' 'Neighbors'." Cultural Critique, No. 27, 127-152.

Silverstein, M. and Xuan C. (1999)."The Impact of Acculturation in Mexican AmericanFamilies on the Quality of Adult Grandchild-Grandparent Relationships.”Journal of Marriage and the Family, Vol. 61, No. 1, 188-198.

Swyt, W.(1998)."Hungry Women: Borderlands Mythos in Two Stories by Helena Maria Viramontes" MELUS, Vol. 23, No. 2, 189-201.

Viramontes, H. (1985). "The Moths" and Other Stories. Houston: Art Public Press.

Yarbo- Bejarano, Y. (1985). Introduction.The Moths" and Other Stories.Viramontes, Helena. Houston: Art Public Press. 